\title{
Upper Crossed Syndrome and Dentistry Why the Need for Concern
}

\author{
S Raja Rajeswari*1, Prem Blaisie Rajula ${ }^{1}$, Triveni M Gowda ${ }^{2}$, Tarun AB Kumar ${ }^{2}$, PL Ravi Shankar ${ }^{1}$, and \\ Dhoom Singh Mehta ${ }^{2}$ \\ ${ }^{1}$ Department of Periodontics, SRM Kattankulathur Dental College, SRM University, India
}

${ }^{2}$ Department of Periodontics, Bapuji Dental College and Hospital, Davangere, India

Received: November 29, 2017; Published: December 05, 2017

*Corresponding author: S Raja Rajeswari, Department of Periodontics, SRM Kattankulathur Dental College, SRM University, India; Email: rajarajeswari.mk@gmail.com

\section{Abstract}

Occupational hazard plays a detrimental role in influencing the quality and quantity of work of dental health care personnel. Basic understanding of the same is essential in terms of improved productivity and progress. Among the work related health concerns, musculoskeletal disorders are perhaps the most common and debilitating. Dentists are prone for improper posture and associated muscle strain. Upper crossed syndrome is an incorrect posture associated musculoskeletal condition with high prevalence. This review article will brief on upper crossed syndrome and its implications in dental workforce, with focus on precautionary and therapeutic measures.

\section{Introduction}

Occupational hazard is an umbrella term, encompassing various short and long term risk factors encountered in the work place. Being un heedful of the potential work environment risk factors will lead to vulnerable state. Dental profession presents a unique platform relating to work burdens and ailments. Occupational Safety and Health Administration has outlined the involved factors related to dentistry, its recognition, control and prevention. Major risk factors included, but essentially not limited are biological, chemical and pharmaceutical hazards, musculoskeletal disorders and ergonomic issues, noise and vibration related hazards and psychological issues [1]. Musculoskeletal disorders (MSD) are key contemporary dental occupational hazard and its reported incidence is as high as $81.4 \%$ [2]. The work related pain was mostly attributed to shoulder, lower back and neck region [3]. Lower back pain had high prevalence of $64 \%$, closely followed by $60 \%$ neck pain, with simultaneous pain in multiple sites tagging behind [4]. Females are found to be at higher risk than that of a male dentist.

The concerned symptoms were reported to occur early in the profession with chronicity noted due to typical late intervention. Reported consequences are socioeconomic burden on the professional with reduced working hours, even early retirement [5]. Long working sesions, sustained static position, awkward posture combined with that of recurrent, repetitive, precise and highly controlled movements are the reasons attributed.5 More frequent and prolonged the aforementioned factors happens to be, more pronounced is the resultant injury, owing to strained muscle, bone and joints. Dental professionals are more prone for prolonged bending; twisted trunk and continuous preordained static posture [6]. A static posture could be one that has been withheld during the whole period of the exertion. In dentistry, static postures with repetitive motion and poor ergonomics leads to a vicious pathway. During a specified treatment time, constrained posture with awkward position of head and trunk is highly observed [7].

\section{Upper crossed Syndrome}

Poor posture has been associated with musculoskeletal imbalance and one such commonly reported condition is Upper crossed syndrome (UCS). Improper posture has been associated with muscle tension and limited mobility [8]. Literature reports that the posture frequently adopted in the upper extremity is forward head posture [9]. UCS is the term coined by Janda and used for such misalignment. He has stated that the maintenance of a stooped sitting posture for an extended period of time is the major predisposing factor [10]. It is also known by other terms such as proximal or shoulder girdle crossed syndrome.

The overactive muscles on one side of the neck are found to counteract the underactive muscles of the adjacent side, creating an ' $\mathrm{X}$ ' pattern. This comprises of reciprocal inhibition, wherein muscles on one side are lengthened to compensate for 
the shortened, contracted muscle on the other side of the joint. With prolonged continued postural imbalance, the intensity of the muscular imbalance increases over time, creating a vicious cycle [10]. The resultant clinical presentation are the complaint of neck and shoulder pain, cervicogenic headache, hunched upper back and rounded shoulders [8]. Owing to the constrained dental clinical work field aka oral cavity, rapid, repetitive, controlled and/ or forceful movements in conjunction with sustained awkward posture, the dental personnel are highly predisposed to UCS [4]. As previously stated, in the literature ample epidemiological studies are published establishing the association of occupational factors and MSD in dentistry. A cross sectional study analysing 220 dental students has ascertained the tendency of increased tightness in the neck extensor and pectoral muscles in dentists [11]. This supports the hypothesis of heightened risk of the dental professionals for developing muscular imbalance and especially, UCS.

However the methodological difficulties are key predicament in generalising the prevalence of such muscular imbalance. Inconsistencies in study design, classification method, outcome variable and interpretation of the results has generated significant controversy in this field. Rapid upper limb assessment (RULA) is a standard method used to assess the ergonomic sitting posture [12]. The number of movements, static muscle force and work are the aspects evaluated in RULA. Muscular length test, muscular strength test, cervical range of motion, forward head posture measurement by craniovertebral analysis, rounded shoulder measure and kyphosis measure are some assessments that will outline the severity of the clinical entity presented [13]. Subsequent to identification of the UCS, proper corrective measures need to be undertaken to correct and limit the muscular imbalance. A recent study assessing 30 dentists with UCS were analysed in a eight week exercise program [14]. A 30 - 60 minutes workout was carried out, with exercises being selected on the basis of individual needs. Warm up, light exercises, special strength and resistance training was the aspects of the training program, with significant positive outcome.

In the upcoming dental profession, preventive program aimed at establishing the habit of improper posture development is critical in curbing this vicious pathological process. Rigorous stress and training on workplace posture maintenance should be stressed upon in dental educative system. Appropriate use of ergonomic instruments will also reduce the unnecessary muscle load. A concept known as 'Active physical movement' during treatment procedures has been advocated by many researchers. Changing posture at regular interval, taking micro breaks, using stretching exercises in between the procedure will potentially reduce the ill-effects of static posture. The stretching exercise is advocated especially in the opposite direction of the static and repetitive posture [15]. Regular work out and/or yoga seems to be beneficial from biomechanical view, but studies doesn't show consistent pattern in this regard [16]. Cultivation of healthier posture habits, early diagnosis and compensatory muscle stretching and relaxation exercises, especially in cervical region could prevent the incidence and severity of UCS.

\section{Conclusion}

Neck, a structurally delicate body segment tasks the huge burden of supporting the human head. Improper body posture inherent in dentistry, paves way for increased incidence of neck pain and UCS. Numerous suggestions are put forth for altering the assumption of awkward posture, including improved equipment ergonomics, favourable workspace up gradation, physical therapy and active life style adaptation. Early identification and prevention of UCS is crucial in preventing further degenerative changes and treating the musculoskeletal pain. Understanding how best to develop to awareness regarding prevention of UCS is a singular agenda of this research field still remaining. Modifying the dentists view on monotonous work, improving awareness of the posture embraced, positive ergonomic improvements perhaps be the cost effective and has long standing benefits.

\section{References}

1. Occupational Safety and Health Administration (2017) Safety and Health Topics Dentistry, USA.

2. Isper Garbin AJ, Barreto Soares G, Moreira Arcieri R, Adas Saliba Garbin C (2017) Musculoskeletal disorders and perception of working conditions: A survey of Brazilian dentists in Sao Paulo. Int J Occup Med Environ Health 30(3): 367-377.

3. Morse T, Bruneau H, Dussetschleger J (2010) Musculoskeletal disorders of the neck and shoulder in the dental professions. Work 35(4): 419-429.

4. Shirzaei M, Mirzaei R, KhajeAlizade A, Mohammadi M (2015) Evaluation of ergonomic factors and postures that cause muscle pains in dentistry students bodies. J Clin Exp Dent 7(3): e414-e418.

5. Al-Shehri Z, Al Zoughool M (2017) Prevalence and risk factors of musculoskeletalvsymptoms among dental students and dental practitioners in Riyadh City Saudi Arabia. Arch Environ Occup Health 14: 1-8.

6. Ohlendorf D, Erbe C, Nowak J, Daniela Ohlendorf, Christina Erbe, et al. (2017) Constrained posture in dentistry a kinematic analysis of dentists. BMC Musculoskeletal Disorders 18: 291.

7. Batham C, Yasobant S (2016) A risk assessment study on work-related musculoskeletal disorders among dentists in Bhopal India. Indian J Dent Res 27(3): 236-241.

8. Moore MK (2004) Upper crossed syndrome and its relationship to cervicogenic headache. J Manipulative Physiol Ther 27(6): 414-420.

9. Yoo WG (2013) Effect of the neck retraction taping (NRT) on forward head posture and the upper trapezius muscle during computer work. J Phys Ther Sci 25: 581-582.

10. Janda MD (2007) Orthopedic physical assessment ( $5^{\text {th }}$ edn) St. Louis: Sauders.

11. Srijessadarak T, Sae-Lee D, Paungmali A, Mato L, Bumrerraj S, et al. (2017) Investigations of upper crossed syndromes characteristics in dental students. Journal of Associated Medical Sciences 50(3): 404-416.

12. L. McAtamney, EN Corlett (1993) RULA: a survey method for the investigation of workrelated upper limb disorders Applied Ergonomics 24(2): 91-99.

13. Seo-Yeung G, Hwangbo G, Lee Y (2016) Relationship between position sense and reposition errors according to the degree of upper crossed syndrome J Phys Ther Sci 28: 438-441.

14. Noroozi F, Rahnama N (2017) Effect of Eight Week Selected Corrective Exercises Syndrome in Dentist. International Journal of Sport Studies $7(1): 37-43$. 
15. SJ Linton, MW van Tulder (2001) Preventive interventions for back and neck pain problems: what is the evidence? Spine 26(7): 778-787.
16. Morse T, Bruneau H, Dussetschleger J (2010) Musculoskeletal disorders of the neck and shoulder in the dental professions. Work 35: 419-429.

$\begin{array}{ll}\text { BIOMEDICAL } & \text { Assets of Publishing with us } \\ \text { RESERCHES } & \text { Global archiving of articles }\end{array}$

